\title{
¡Esos Altos de Jalisco!
}

ANDRÉS FÁBREGAS PUIG ${ }^{1}$

\begin{abstract}
Al iniciarse el régimen colonial en el siglo XVI en lo que es actualmente nuestro país, México, los Altos de Jalisco no existían como tales. Precisamente la formación de una región con ese nombre en el actual estado de Jalisco se inició al momento en que los españoles intentan avanzar hacia el norte y el occidente, una vez que se han establecido en la destruida Gran Tenochtitlán y han fundado los cimientos de la actual Ciudad de México. Fundada la ciudad de Guadalajara y establecida allí la Audiencia de la Nueva Galicia, es esta institución la que controló administrativamente el poblamiento del vasto territorio que se abría hacia el norte de nuestro país. En esas amplias latitudes los españoles se enfrentaron con sociedades diferentes a las que se encontraron en el centro, en los valles de México, alrededor de la zona de lagos. En las zonas de ciudades como la Gran Tenochtitlán los pueblos originarios eran cultivadores de alto nivel que conocían técnicas agrícolas complejas de regadío y poseían una ingeniería muy adelantada para la construcción de grandes obras como diques, canales,
\end{abstract}

I Ciesas-Occidente. 
puentes, además de los cultivos de almácigo conocidos como chinampas practicados en el lago de Xochimilco. Muy diferente era la situación hacia el norte o noroccidente y nororiente del centro de México. En estas últimas regiones los españoles se encontraron con los grupos nómadas, cazadores fundamentalmente, pero que también conocían los cultivos. Su vida transcurría en amplios territorios de cacería y de recolección de frutos y yerbas, con lo que se alimentaban. Fueron un gran número de pueblos diferentes como los guachichiles, huamares, zacatecos, cocas, tecuexes, pimas, y un largo número más de grupos conocidos todos bajo el apelativo de chichimecas. Estos grupos presentaron una tenaz resistencia al avance español, siendo protagonistas de la llamada guerra chichimeca, que se prolongó cerca de 200 años. Una de las batallas más cruentas entre chichimecas y españoles, más los tlaxcaltecas y purépechas aliados de éstos, se llevó a cabo en el peñón del Mixtón, situado en el actual estado de Zacatecas, hacia el año de 1542. Esa batalla fue tan difícil de ganar para los españoles, que decidieron transportar a pastores-soldados traídos desde las sierras de Castilla para que poblaran las tierras que hoy conocemos como los Altos de Jalisco. El virrey Antonio de Mendoza escogió a grupos de estos pastoressoldados que tenían experiencia en batallar contra los musulmanes y que se distribuían por el campo charro de Salamanca, la Sierra de Ávila y la Sierra de Gredos, así como en la Peña de Francia, lugares de España desde los que fueron trasladados a tierras de la Nueva Galicia. El Estado español prometió que las tierras que estos pastores-soldados lograran defender de los chichimecas les serían concedidas en propiedad privada. Además, deberían de formar una barrera que garantizara el avance español hacia el norte, hasta tierras tan lejanas como los actuales estados de Arizona, California, Nuevo México y Texas, conteniendo siempre los ataques de chichimecas, apaches, comanches y otros pueblos. El plan del virrey Antonio de Mendoza tuvo éxito y así nacieron, entre otras regiones mexicanas, los Altos de Jalisco.

Los pastores-soldados que vinieron a poblar las vastas latitudes del centro-occidente y del norte de México eran expertos criadores de ganado vacuno, caballar y lanar. Con trabajo tesonero fueron extendiendo los rebaños y los hatos, surtiendo desde los Altos de Jalisco a las regiones 
mineras que demandaban mulas y alimento para los mineros. Convirtieron a los Altos de Jalisco en una región distribuidora de población y desde allí emigraron, con todo y animales, hacia el norte central, el noroeste y el noreste del país. Fueron estos ganaderos quienes fundaron Nuevo León o la región de La Laguna y llevaron sus hatos tan lejos como lo que es hoy el suroeste de Estados Unidos. Son ellos quienes inventaron el rodeo, tan característico de las fiestas rancheras del sur de Norteamérica. Eran y siguen siéndolo profundamente católicos y devotos. Se adaptaron a sus nuevas tierras mezclando sus ancestrales costumbres con las que surgieron en sus nuevos hogares. Se convirtieron en ganaderos de trigo y maíz, consumiendo igualmente el pan y la tortilla. Inventaron la charrería como un pasatiempo mientras trabajaban con los animales, herrándolos o marcándolos con los símbolos de sus propietarios. De hecho, la charrería tiene su antecedente inmediato en los herrajes, es decir, en los momentos de reunión de los ganaderos alteños para herrar y marcar sus animales mientras conviven comiendo y bebiendo el tequila, otro brebaje inventado por ellos. Con el transcurrir del tiempo los alteños hicieron prosperar sus ranchos y haciendas, además de edificar ciudades como Tepatitlán, Arandas, Yahualica, San Miguel el Alto, Jalostotitlán, Teocaltiche, San Juan de los Lagos o Lagos de Moreno. En varias de estas ciudades existen centros internacionales de peregrinación. El más concurrido es San Juan de los Lagos, cuya Catedral guarda la imagen de la Virgen de San Juan, famosa por sus milagros y que recibe a más de cuatro millones de peregrinos anualmente. Son estos ganaderos alteños quienes sostuvieron la llamada Guerra Cristera en los años 1926-I929, uno de los episodios más complejos de la historia mexicana y cuyos resultados son importantes para entender los rumbos del país. Hacia la época del gobierno de Lázaro Cárdenas los rasgos culturales de los ganaderos de los Altos de Jalisco se generalizaron a través del cine como símbolos que distinguían a la nacionalidad mexicana. Tales son el tequila, como la bebida nacional; la charrería, como el deporte nacional, y la vestimenta de los charros como traje nacional. El mariachi, muy extendido en los Altos de Jalisco, se convirtió en la música nacional. Aún estamos a la espera de una explicación documentada de 
por qué sucedió así, pero en una época el país fue identificado culturalmente por esos símbolos provenientes del estado de Jalisco.

Los Altos de Jalisco han tenido un papel importante en el desarrollo de la antropología en México. Dicha disciplina nació junto con el Estado nacional en el siglo XIX. En los momentos en que se consumaba la independencia de México, los círculos liberales que llegaron al poder pensaban en cómo consolidar a una nación que, como la mexicana, presentaba una variedad cultural notable. Las sociedades rancheras, como la de los Altos de Jalisco, no entraban en esta preocupación. El llamado problema de integración nacional se localizaba, a ojos de los intelectuales liberales, en los pueblos originarios, en los indígenas. Concibieron a la antropología como una disciplina apta para coadyuvar en la consolidación de la nación. En el siglo xx, con la disciplina antropológica más desarrollada, se concibió la teoría de la aculturación como el instrumento idóneo para lograr que los pueblos originarios completaran un ciclo aculturativo que desembocaría en la creación empírica del prototipo del mexicano: el ranchero al estilo de los Altos de Jalisco. Toda una época del cine mexicano fue dedicada a apuntalar esta visión del mexicano promedio. Entre los antropólogos fue Alfonso Caso uno de los que más impulsó esta corriente, que el antropólogo veracruzano Gonzalo Aguirre Beltrán vino a desarrollar y consolidar.

En el sexenio en el que gobernó el general Lázaro Cárdenas del Río (I934-I940) tuvieron lugar importantes acontecimientos relativos al impulso de la teoría de la aculturación y la meta de llegar a consolidar a una sociedad nacional con una cultura nacional. De esta manera se crearon instituciones que tuvieron como objetivo lograr la aculturación de los pueblos originarios. El principal acontecimiento, aún gobernando Lázaro Cárdenas, fue la celebración del Congreso Indigenista Interamericano celebrado en Pátzcuaro, Michoacán, entre el I4 y el 24 de abril de I940, que puso las bases para ulteriores instituciones. Entre esas instituciones, la principal para los propósitos del Estado nacional mexicano respecto a las culturas y pueblos originarios, fue el establecimiento del Instituto Nacional Indigenista (I94I) y la Escuela Nacional de Antropología e His- 
toria (1940). Previamente, en I939, se había creado el INAH, con el objetivo de proteger y enriquecer el patrimonio nacional.

La inclinación de la antropología en México se volcó en el estudio de los pueblos indígenas. Fue así porque el propósito del Estado era crear y consolidar una sociedad nacional, sellada con una cultura nacional, que pudiese identificar a todos los habitantes del territorio concebido como nacional, como un conjunto homogéneo culturalmente hablando. Ello explica el que en los programas de estudio de la Escuela Nacional de Antropología e Historia, que por años fue el único centro en donde se formaron los antropólogos mexicanos, no incluyera en sus planes de estudio a sociedades regionales como la de los rancheros de los Altos de Jalisco. Durante años, la discusión entre los antropólogos mexicanos giró en torno a cómo lograr la aculturación de los pueblos indígenas y cómo integrarlos a un prototipo de cultura nacional que aportaba sus símbolos desde el estado de Jalisco. Incluso, la principal industria del país y propiedad del Estado nacional, Petróleos Mexicanos (Pemex), tuvo como emblema a un charro: "El Charrito Pemex", que aparecía en los anuncios cinematográficos o en pósters y carteles.

Si se revisa la bibliografía producida desde la fundación de la Escuela Nacional de Antropología e Historia (ENAH) hasta entrada la década de los años 1970, se observará el abrumador predominio de las etnografías sobre los pueblos indígenas. En congruencia, las regiones para llevar a cabo el "trabajo de campo" característico de los antropólogos se localizaban en los hábitats indígenas, por ejemplo: los Altos de Chiapas, la Sierra Tarahumara, el territorio de los coras y huicholes, la región totonaca o bien los pueblos mayas de Campeche y Yucatán. Todavía la generación de estudiantes que ingresó a la ENAH en 1965, a la cual pertenezco, fue educada para estudiar los pueblos indígenas, aunque ya se perfilaba la crítica al llamado "indigenismo mexicano", con jóvenes —en aquella épocacomo Guillermo Bonfil, Margarita Nolasco, Arturo Warman, Mercedes Olivera, Enrique Valencia o José Rendón, entre otros. En 1970 se publicó el libro De eso que llaman antropología mexicana, coordinado por Arturo Warman, en cuyas páginas una generación de antropólogos y antropólogas mexicanas expusieron una crítica profunda al indigenismo y a la teoría 
de la aculturación. Sin entrar en más detalles, apunto que el movimiento estudiantil de 1968 constituyó un parteaguas en la antropología mexicana, al provocar la profundización de la crítica al indigenismo y alentar la búsqueda de nuevos temas en la antropología mexicana. Papel destacado en este sentido desempeñó Ángel Palerm, al apoyar el surgimiento de nuevos nichos de estudio y de nuevas instituciones para albergar los nuevos rumbos de la antropología que emergía en el país.

Precisamente fue en una discusión con Ángel Palerm que surgió el tema de los Altos de Jalisco. Era el año de 1972, a mediados, recién regresado de mis estudios de posgrado en la Universidad Estatal de Nueva York en Stony Brook. Platicamos en los locales que Palerm ocupaba en la Universidad Iberoamericana, situada en aquellos años en la Avenida de las Torres, en el entonces Distrito Federal. Le expuse a Palerm mi intención de escribir un texto destinado a ser presentado como tesis para obtener el doctorado en antropología social. Estuvimos explorando posibilidades, iniciando por descartar el estudio de alguna región indígena, no obstante que soy nativo del estado de Chiapas. Además, me interesaba aplicar un método que combinaba a la economía política (Marx) con la ecología-cultural (Steward; Palerm; Krader). Todo ello dentro de un enfoque regional. Se trataba de aportar a los enfoques para superar el "estudio de la comunidad", tan en boga en aquellos años, en que predominaba el indigenismo y su par, el desarrollismo.

El estudio que coordiné en los Altos de Jalisco resultó ser pionero en el campo de la reflexión sobre grupos humanos no indígenas, elaborada por antropólogos mexicanos. Estuve al frente de un grupo de estudiantes de la Universidad Iberoamericana, que redactaron sus tesis de licenciatura en antropología social apoyados en su experiencia alteña (Fábregas, 1986). Comenzamos por recorrer la región, reconociendo sus características, su variedad ecológica, ambiental y cultural, su vocación ganadera dominante en aquellos años iniciales de la década de 1970. Fuimos de sorpresa en sorpresa, adentrándonos en la vida campirana de una región que es central en la configuración de una "identidad mexicana”. Aún no existía la macro pista y la comunicación entre Guadalajara, la capital de Jalisco y la ciudad al extremo norte de los Altos, Lagos de Moreno, se 
hacía por la ahora "vieja" carretera, camino que pasaba por varios poblados y pequeñas ciudades. El tiempo en recorrer esa ruta entre Lagos de Moreno y Guadalajara era de entre cinco a seis horas, según vehículo y velocidad de traslado. Viniendo de Guadalajara, Acatic es el primer municipio alteño que atraviesa la carretera. Dada la composición del grupo de estudiantes y su número, pudimos abarcar varios temas, desde la historia de la configuración regional de los Altos, pasando por el estudio de la ganadería, la urbanización, la confección de tacones para zapatos, la vida política y los grupos de poder, la religión, la organización de la tenencia de la tierra, las formas del parentesco y la Guerra Cristera. En otras publicaciones he hablado de estos aportes y de la composición del grupo de estudiantes (Fábregas, 20II).

Lo más significativo de aquella primera experiencia en los Altos de Jalisco fue el abrir un nuevo campo de estudio para la antropología mexicana: las sociedades de rancheros y sus ámbitos regionales. He aquí una sociedad de pequeños propietarios, huraños ante la reforma agraria y todo lo que implique reparto de la tierra desde el Estado; existieron las haciendas, pero justo en los bordes de la región, como la de Ciénega de Mata. Notamos el predominio del mestizo alteño, de un prototipo que anuncia sus orígenes ibéricos - aunque la leyenda sigue insistiendo en que son franceses- de gente de frontera. Advertimos la presencia indígena, pero no en la forma de organización comunal para la época prehispánica, sino más bien los pequeños grupos errantes característicos de los grupos nómadas. No se nos pasó registrar la presencia de tlaxcaltecas, y otros grupos originarios, llegados hasta los Altos acompañando a los castellanos. Anotamos la presencia de la población de origen africano, ya en la época colonial, en su papel de expertos arreadores del ganado, o bien como sirvientes domésticos. No tardamos en caer en cuenta en el enorme poder de la Iglesia católica, articuladora cultural y política de la población alteña. La Guerra Cristera nos descubrió ángulos básicos de la organización de estas sociedades y su profundidad histórica. Nos ayudó a entender por qué el rechazo a la reforma agraria y a la intervención del Estado en los asuntos de la sociedad. Lo supimos al estudiar las formas del parentesco y sus normas de herencia. Fue un estudio que arrojó 
importantes resultados para entender la composición de los grupos de poder y sus estrategias para normar el acceso a los recursos básicos de esta sociedad regional. No tardamos en caracterizar a los Altos de Jalisco como una región de pequeños propietarios, rancheros, ganaderos, hombres y mujeres de a caballo, católicos y fronterizos.

Años después de aquella primera experiencia, Pedro Tomé y yo emprendimos en los estertores del siglo xx el estudio comparado de los Altos de Jalisco y la Sierra de Ávila en España. Por vez primera, un antropólogo español y otro mexicano llevaban a cabo un análisis, con trabajo de campo y con reflexiones conjuntas. Fue una experiencia importante e interesante que dejó, entre otros resultados, tres libros (Tomé y Fábregas, 1999; Fábregas y Tomé, 200I; Tomé y Fábregas, 2002). Pedro Tomé y yo recorrimos la Sierra de Ávila y los Altos de Jalisco palmo a palmo. Por mi parte, descubrí el campo charro, la gran ciudad de Salamanca, capital de la Cultura Charra de Castilla, la Peña de Francia, hogar de varios grupos de parientes que llegaron a los Altos de Jalisco y la impresionante ciudad de Ávila, que aún conserva la Muralla que la hizo famosa. Observamos la estrecha similitud entre los lienzos de los Altos de Jalisco y las bardas de piedra de la Sierra de Ávila. Un profundo catolicismo caracteriza a los habitantes de ambas regiones. Tan católicos allá como acá. Tan criadores de ganado allá como acá. El físico de las personas, muy cercano, si a la población de origen ibérico en los Altos nos referimos. Gente de frontera y de a caballo, también en ambas regiones. Muchos apellidos de los Altos tienen su origen en la Sierra de Ávila: Martín, Zermeño, Gutiérrez, Serrano, Aceves. Los rancheros de los Altos de Jalisco entraron a la antropología de España y los serranos ganaderos, de la Sierra de Ávila, hicieron presencia en la antropología mexicana.

En ambas regiones los antropólogos logramos un buen entendimiento con la gente. Entramos a sus casas, bebimos de su vino en Ávila y de su tequila en los Altos. Saboreamos la carne del ganado criado en ambas regiones. Conversamos largo con los rancheros alteños y con los ganaderos y pastores abulenses. Pedro Tomé es un personaje reconocido en los Altos, tanto, que aparece en un mural del Museo de Tepatitlán. En una noche memorable en esta última ciudad, se le declaró hijo predilecto. 
Gracias a nuestro trabajo conjunto en ambas regiones se pusieron las bases para que lleváramos a cabo un inolvidable encuentro entre antropólogos españoles y mexicanos, que recorrió los Altos de Jalisco. En Ávila, con el imponente escenario de la Muralla, presentamos nuestros libros ante concurrida presencia. Incluyó un embajador mexicano en España que había pasado su luna de miel precisamente en Ávila. En una palabra: ese estudio comparado contribuyó a acercar a las antropologías de España y de México.

En la antropología mexicana, los Altos de Jalisco tienen el importante papel de haber contribuido, como sociedad, a la pluralidad temática de la disciplina. Los primeros trabajos sobre los Altos de Jalisco plantearon preguntas y problemas que dieron origen al desarrollo de múltiples investigaciones posteriores. Sólo citar esa bibliografía nos llevaría varias páginas. Más todavía, los trabajos pioneros en los Altos alentaron la formación de antropólogos alteños que hoy hacen una antropología reflexiva muy interesante e importante. Se marcó un comienzo. En la actualidad, los trabajos sobre los Altos de Jalisco han confirmado las añejas hipótesis de los trabajos pioneros, tanto como han derrumbado otras. De eso, justamente, se trata la ciencia. Al derrumbar, construimos nuevas rutas de conocimiento que, sin embargo, no hubiesen sido posibles sin los primeros intentos. A los Altos de Jalisco llegamos un grupo de antropólogas y antropólogos mexicanos cuando aún predominaban en el país los estudios sobre los grupos indígenas. Parecía increíble que no hubiesen llamado la atención de los antropólogos las regiones rancheras como la de los Altos de Jalisco, que han cumplido un papel destacado en la forja de los símbolos culturales de la macro identidad mexicana. No es sólo el antropólogo quien contribuye al conocimiento, sino la sociedad que los provee. Justo es el caso de los Altos de Jalisco.

En la actualidad los Altos de Jalisco son una región muy próspera dedicada a la ganadería de leche, la fabricación de tequila y en general a la industria de alimentos como pollo, huevos y derivados lácteos. Sus habitantes se caracterizan además por portar una doble nacionalidad: la mexicana y la estadounidense. Los alteños van y vienen de California o Texas, estados de la Unión Americana en donde han reproducido sus hábitos culturales 
formando círculos de alteños muy activos que incluyen equipos de futbol y de charrería. Incluso se han establecido en ciudades tan lejanas como Chicago, en donde dominan la industria restaurantera. La importancia de los Altos de Jalisco es tal que la Universidad de Guadalajara ha establecido dos campus universitarios: en Tepatitlán y en Lagos de Moreno. En esa tierra han nacido historiadores tan ilustres como Agustín Rivera o poetas tan finos como Alfredo R. Plascencia. Los alteños de Jalisco han contribuido y contribuyen con su trabajo y su mexicanidad acendrada al desarrollo del país. Como dice la canción: “¡Esos Altos de Jalisco! Qué bonitos”.

Ajijic. Ribera del Lago de Chapala, marzo 2019.

\section{Referencias bibliográficas}

Fábregas Puig, Andrés. (1986). La formación histórica de una región: Los Altos de Jalisco. México: CIESAs, Col. Othón de Mendizábal, núm. 5 .

-_. (2011). Configuraciones regionales mexicanas. Un planteamiento antropológico. México: Gobierno del Estado de Tabasco/Cimbestab.

Fábregas Puig, Andrés, y Tomé Martín, Pedro. (200I). Entre parientes. Estudios de caso en México y España. México: El Colegio de Jalisco/Institución Gran Duque de Ávila, España.

Tomé Martín, Pedro, y Fábregas Puig, Andrés. (1999). Entre mundos. Relaciones interculturales entre México y España. México: El Colegio de Jalisco/Institución Gran Duque de Alba, España.

- - (2002). Regiones y fronteras. Una perspectiva antropológica. México: El Colegio de Jalisco.

Warman, Arturo, et al. (1970). De eso que llaman antropología mexicana. México: Nuestro Tiempo. 